\title{
Impact Of Ozone Concentration On Ocean Colour Retrievals For OCM-2
}

\author{
I.V.G.Bhavani ${ }^{1 *}$, T.D.V.P.Rao ${ }^{1}$, Anupam Das ${ }^{1}$, S.B.Choudhury ${ }^{1}$, P.V.Nagamani ${ }^{1}$, K.V.S.R.Prasad ${ }^{2}$, S.K.Sasmal ${ }^{1}$ \\ ${ }^{1}$ National Remote Sensing Centre, Hyderabad - ivg.bhavani123@gmail.com \\ ${ }^{2}$ Department of meteorology and Oceanography, Andhra University, Visakhapatnam
}

Commission V, SS: Atmosphere, Ocean, Weather and Climate

KEY WORDS: OMI / Aura, SeaDAS , OCM-2, NRT

\begin{abstract}
:
Ozone being an absorbing gas have a significant impact on OCM-2 bands $510 \mathrm{~nm}, 555 \mathrm{~nm}$ and $620 \mathrm{~nm}$ which are using for retrieval of major geophysical parameters like Chlorophyll and suspended sediment concentrations. A study has been carried out to analyse the impact of Ozone concentration by ingesting near real time from OMI (Ozone Monitoring Instrument) on Aura instead of Climatology V2013(2004 - 13) with a resolution of 1x1 deg for ocean colour retrievals from OCM-2 sensor using SeaWiFS Data Analysis System (SeaDAS). The spectral behaviour of Ozone transmittance has been studied for various bands of OCM-2 by using both Climatology and near real time inputs. We could observe maximum relative error percentage about $12 \%$ from Climatology to NRT in Ozone concentration and $0.28 \%, 0.66 \%$ and $0.72 \%$ of maximum mean relative error in ozone transmittance at $512 \mathrm{~nm}, 557$ $\mathrm{nm}$ and $620 \mathrm{~nm}$. We calculated error budgets induced by ozone in remote sensing reflectance(/sr) where in we could observe mean relative error percentage of $0.52 \%$ in $491 \mathrm{~nm}, 1.12 \%$ in $512 \mathrm{~nm}$ and $4.28 \% 557 \mathrm{~nm}$ a bands respectively.
\end{abstract}

\section{INTRODUCTION}

Improvement in the retrieval of geophysical products from Ocean Color Monitor-2 is objective of this study. To achieve this, one approach is to ingest near real time Meteorological and Ozone data. Radiance from the sea surface reaching to any ocean color sensor undergoes gaseous absorption. It affects the magnitude of radiance. Ocean color processing involves removal of atmospheric components from sensor measured top of the atmosphere radiance ( $\mathrm{Lt})$. Lt can be written as (Franz et al., 2007, Eq. 1)*

$\operatorname{Lt}(\lambda)=(\operatorname{Lr}(\lambda)+[\operatorname{La}(\lambda)+\operatorname{Lra}(\lambda)]+\operatorname{tdvLwc}(\lambda)+\operatorname{tdv}$ $\operatorname{Lw}(\lambda)) \operatorname{tgvtgsfp}$

$\operatorname{Lr}(\lambda)$ is the Rayleigh radiance due to molecular scattering, $\operatorname{La}(\lambda)$ is the aerosol radiance, $\operatorname{Lra}(\lambda)$ is the interaction term between aerosol and molecular scattering, $\operatorname{Lwc}(\lambda)$ is the whitecap radiance, $\operatorname{Lw}(\lambda)$ is the water leaving radiance, $\operatorname{tdv}$ is the diffuse transmittance along the sensor viewing path, $\operatorname{tgv}$ is the gaseous transmittance in surface to sensor path, tgs is the gaseous transmittance in sun to surface path and fp polarization correction factor. In the process of atmospheric correction gases absorption removes at first. As of now, Gaseous transmittance is computing for eight gases namely Ozone $(\mathrm{O} 3)$, Oxygen $(\mathrm{O} 2)$, $\mathrm{CO} 2, \mathrm{CO}, \mathrm{H} 2 \mathrm{O}, \mathrm{CH} 4, \mathrm{~N} 2 \mathrm{O}, \mathrm{NO} 2$ in sun to surface direction and surface to sensor direction. It is a component quantifying the total losses due to eight gases based on its impact. In the above gases $\mathrm{CO}, \mathrm{N} 2 \mathrm{O}, \mathrm{CO} 2$ and $\mathrm{CH} 4$ have negligible absorption in the Visible and NIR wavelengths (Mobley et al., 2016). Ozone transmittance is a function of Ozone concentration and air mass of the atmosphere, it decreases with increasing concentration and air mass.

Ozone transmittance $\mathrm{tO} 3=\exp [-\tau \mathrm{O} 3 \mathrm{M}]$

$\mathrm{M}=1 / \cos \theta_{\mathrm{s}}+1 / \cos \theta_{\mathrm{v}}$ is the air mass to account for atmospheric path length, $\theta_{\mathrm{s}}$ is the solar zenith angle, $\theta_{\mathrm{v}}$ is the sensor zenith angle. $\tau \mathrm{O} 3(\lambda)=[\mathrm{O} 3] \mathrm{kO} 3(\lambda)$

[O3] Ozone concentration in $\mathrm{cm}(1000 \mathrm{DU}=1 \mathrm{~atm}-\mathrm{cm}), \tau \mathrm{O} 3(\lambda)$ is the optical thickness of the ozone for a vertical path through the atmosphere, $\operatorname{kO} 3(\lambda)$ is the ozone absorption in $/ \mathrm{cm}$.

\begin{tabular}{|c|c|c|}
\hline $\begin{array}{l}\text { Sensor } \\
\text { Specifications }\end{array}$ & OCM-2 & OMI \\
\hline $\begin{array}{l}\text { IGFOV at } \\
\text { nominal altitude } \\
\text { (m) }\end{array}$ & $360 \times 236 \mathrm{~m}$ & $\begin{array}{l}3 \mathrm{~km} \text {, binned to } \\
13 \times 24 \mathrm{~km}\end{array}$ \\
\hline Inclination & $98.28^{\circ}$ & $98.7^{\circ}$ \\
\hline Swath width & $1420 \mathrm{~km}$ & $2600 \mathrm{~km}$ \\
\hline Altitude & $724 \mathrm{~km}$ & $705 \mathrm{~km}$ \\
\hline Spectral bands & $\begin{array}{l}\text { Band 1: } 404-424 \mathrm{~nm} \\
\text { Band 2: } 431-451 \mathrm{~nm} \\
\text { Band 3: } 476-496 \mathrm{~nm} \\
\text { Band 4: } 500-520 \mathrm{~nm} \\
\text { Band 5: } 546-566 \mathrm{~nm} \\
\text { Band 6: } 610-630 \mathrm{~nm} \\
\text { Band 7: } 725-755 \mathrm{~nm} \\
\text { Band 8: } 845-885 \mathrm{~nm}\end{array}$ & $\begin{array}{l}\text { Visible: } 350- \\
500 \mathrm{~nm} \\
\text { UV-1: } 270-314 \\
\mathrm{~nm} \\
\text { UV-2: } 306-380 \\
\mathrm{~nm}\end{array}$ \\
\hline $\begin{array}{l}\text { Equatorial } \\
\text { crossing time }\end{array}$ & $12 \pm 10$ minutes & 13.45 \\
\hline Launch date & September 2009 & July 15,2004 \\
\hline Repeat cycle & 2 Days & 16 days \\
\hline
\end{tabular}

Tabel 1: Specifications of the sensors Ocean Color Monitor-2 (OCM-2) and Ozone Monitoring Instrument (OMI) used in the present study

${ }^{*}$ Corresponding author 


\section{Methodology}

In operational ocean color processing using SeaWiFs Data Analysis System, Ozone transmittance computed by using Ozone daily climatology data of 2004 to 2013 from OMI-Aura about $1 \mathrm{x} 1 \mathrm{deg}$ resolution. Here we examined the impact of Ozone concentration by computing relative error percentage in Ozone transmittance by using daily climatology and NRT data for 16 scenes of OCM-2 for the month of January 2017 (path: 009 and row: 013) by assuming the parameter generated using climatology data is a true value.

Re lative error perentage $=\left|\frac{C \lim \text { ato } \log y \text { parameter }- \text { near rael time paramater }}{c \lim \text { ato } \log y \text { parameter }}\right| X 100 \%$

Generated histograms for the open ocean region in Arabian sea of North $21.50^{\circ}$ South $17.52^{\circ}$ East $72.39^{\circ}$ and West $63.93^{\circ}$. Binwidth used for computing the histogram for the relative error percentage in remote sensing reflectance is 0.1 . Wavelengths $491 \mathrm{~nm}, 512 \mathrm{~nm}, 557 \mathrm{~nm}$ and $620 \mathrm{~nm}$ are central wavelengths of OCM-2 channels have significant influence by Ozone transmittance. Remote sensing reflectance $\operatorname{Rrs}(/ \mathrm{sr})$ is a fundamental geo-physical quantity to retrieve Chlorophyll-a concentration. It's a ratio of Normalized water leaving radiance $\mathrm{nLw}(\mathrm{W} / \mathrm{m} 2 / \mu \mathrm{m} / \mathrm{sr})$ to the extra terrestrial solar irradiance $\mathrm{F} 0(\mathrm{~W} / \mathrm{m} 2 / \mu \mathrm{m})$. $\mathrm{nLw}$ is the radiance emerging from water, normalized to the geometry of sensor and F0 is the extra terrestrial solar irradiance at mean Earth - sun distance.

\subsection{Quality flags}

In ocean color processing quality flags are assigned to each pixel to explain the quality of a pixel, one pixel can have more than one flag. Few quality flags analyzed in this study are ATMWARN, COCCOLITH, COASTZ and TURBIDW. ATMWARN flag is a condition for a pixel having epsilon values $0.85>$ epsilon > 1.35, COASTZ flag is set when depth < $30 \mathrm{~m}$, TURBIDW flag is a condition for a pixel having $\operatorname{Rrs}(670$ $\mathrm{nm})>0.0012(/ \mathrm{sr})$.

\section{Results and Discussions}

Gaseous transmittance is the total transmittance of atmospheric column due to eight gases. Ozone gas only have considered in the present study due to its significant attenuation in visible wavelengths. The dates having relative error percentage with significant high frequency in Ozone transmittance is also showing significant percentage of relative error remote sensing reflectance(/sr).
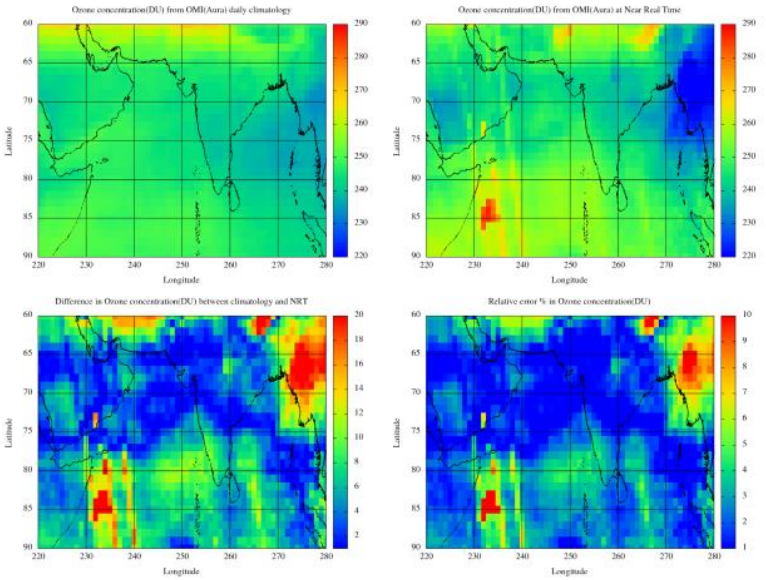

Figure 1: Ozone concentration (DU) from OMI (Aura) of daily climatology (top left) and near real time (top right) difference between climatology and NRT (bottom left) and relative error percentage wrt climatology (bottom right) about 1 x 1 deg spatial resolution for North Indian Ocean East: $40^{\circ}$ West: $100^{\circ}$ North: $0^{\circ}$ South: $30^{\circ}$ on 03 JAN 2017.

Figure plotted using daily climatology ozone data of $1 \mathrm{x} 1 \mathrm{deg}$ (180 x 360) from SeaDAS ancillary support files and NRT downloaded from OCEAN COLOR WEB on 03 JAN 2017 and coastline overlaid on ozone file. Latitude represented by $0{ }^{\circ}$ to $180^{\circ}$ and longitude represented by $0^{\circ}$ to $360^{\circ}$.

Ozone concentration (DU) of daily climatology on 03 JAN 2017 for North Indian Ocean is showing consistent behaviour about 240 to $260 \mathrm{DU}$, but details of greater than $290 \mathrm{DU}$ and less than 220 DU could not seen in daily climatology. For the specific day on 03 JAN maximum observed difference is 20 DU and 10 to $12 \mathrm{DU}$ difference can be seen in $0^{\circ} \mathrm{N}$ (Equator) to 10 ${ }^{\circ} \mathrm{N}$ latitude of water surface.

Relative error percentage in Ozone concentration have computed using daily climatology and NRT concentration. Minimum relative error percentage of $0.50 \%$ and $0.54 \%$ have observed on $01 \mathrm{JAN}, 03 \mathrm{JAN}$ and maximum relative error percentage observed is $10.39 \%$ on 23 JAN , $8.92 \%$ on 25 JAN respectively.

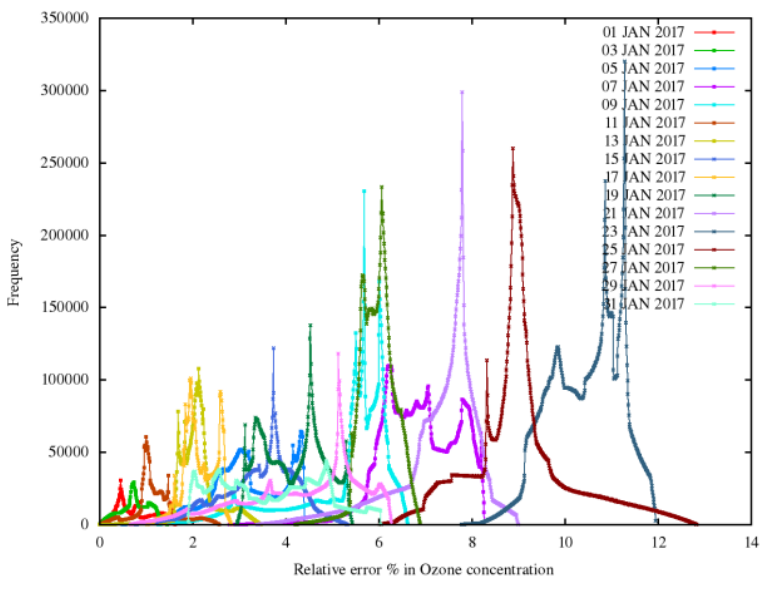

Figure 2: Histograms of Relative error percentage in ozone concentration between daily climatology and near real time for January 2017 

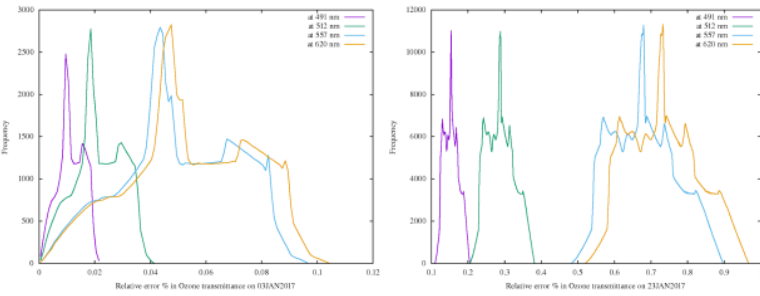

Figure 3: Histograms of Relative error percentage in Ozone transmittance (dimensional less) at 491, 512, 557 and $620 \mathrm{~nm}$ for OCM-2 on 03 January and 23 January 2017.

The spectral behaviour of Ozone transmittance can be seen in figure 3 between $491 \mathrm{~nm}, 512 \mathrm{~nm}, 557 \mathrm{~nm}$ and $620 \mathrm{~nm}$ wavelength for January 2017. Relative error percentage is showing high values with increasing wavelength. Among 16 days low and high mean relative error percentage only presented here. For the specific day histogram pattern needs to be analysed further.
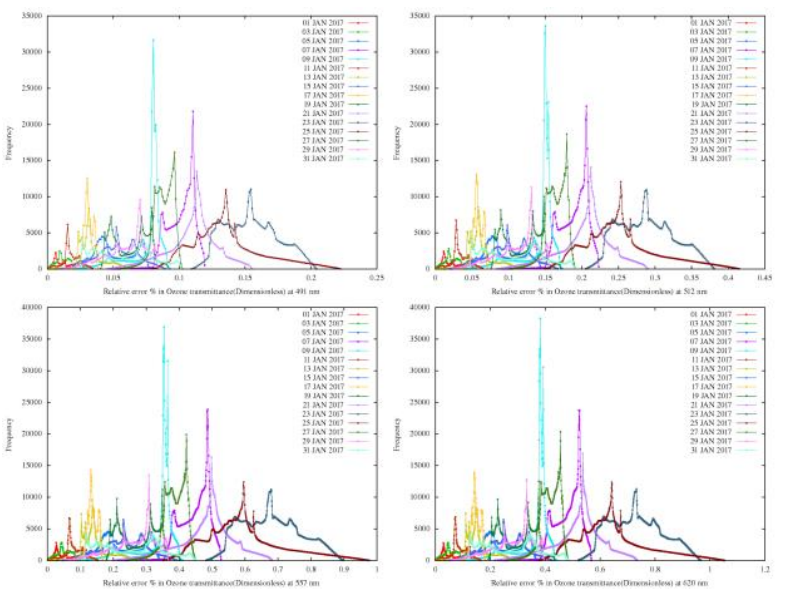

Figure 4: Histograms of Relative error percentage in Ozone transmittance (dimensionless) at $491 \mathrm{~nm}, 512 \mathrm{~nm}, 557 \mathrm{~nm}$ and $620 \mathrm{~nm}$ wavelength for the month of January 2017
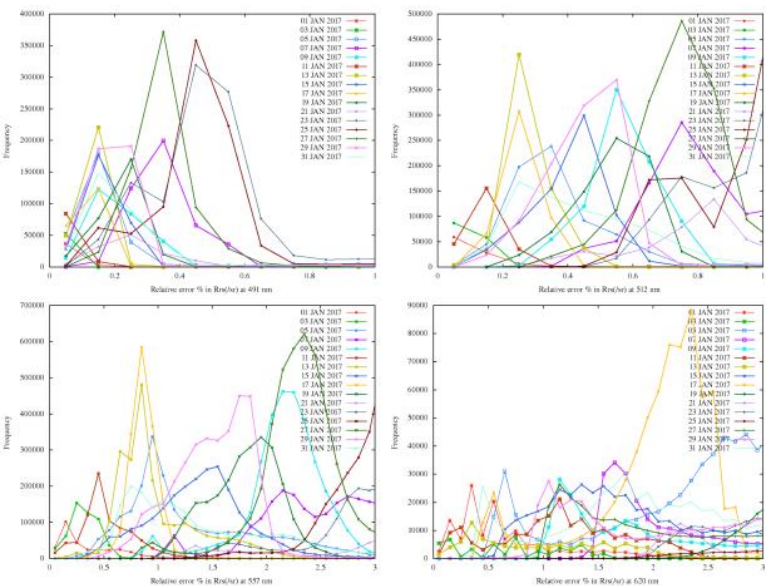

Figure 5: Histograms of Relative error percentage in Rrs (/sr) at $491 \mathrm{~nm}, 512 \mathrm{~nm}, 557 \mathrm{~nm}$ and $620 \mathrm{~nm}$ wavelength for the month of January 2017

Initially, magnitude of deviation computed between retrieved remote sensing reflectance (/sr) when daily climatology and near real time Ozone concentration have used. And computed relative error percentage w.r.t daily climatology. The relative error about $2 \%$ can be positive or negative value. Minimum relative error percentage in $\operatorname{Rrs}(/ \mathrm{sr})$ is 0.02 , most of the days ranging to 0.6 at $491 \mathrm{~nm}$, at $512 \mathrm{~nm}$ its ranging to $1 \%$, at 557 $\mathrm{nm}$ its showing $8 \%$ of relative error. We are focussing on wavelength of $557 \mathrm{~nm}$ which is using as base band in retrieval of chlorophyll-a (OC2 \& OC4) concentration (O'Reilly et al., 1998). Rrs (/sr) showing minimum on 03 JAN and maximum relative error is $8 \%$ on $23 \mathrm{JAN}$. The mean relative error $8 \%$ in rrs means retrieved rrs from climatology is having 0.00008 (/sr) if we taken the maximum possible rrs (/sr) (for eg $0.01 / \mathrm{sr}$ ) at $557 \mathrm{~nm}$ wavelength. Further analysis required to see the impact of ozone on chlorophyll concentration $(\mathrm{mg} / \mathrm{m} 3)$. The days 21 JAN, 23 JAN showing maximum mean relative error percentage having high relative error percentage $7.16 \%$ and $10.39 \%$ in Ozone concentration (DU) respectively. And minimum relative error percentage in rrs (/sr) have observed on $03 \mathrm{JAN}$ having $0.54 \%$ percentage of deviation in Ozone concentration.
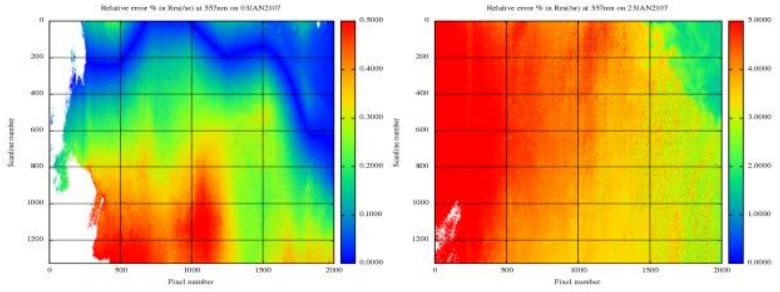

Figure 6: Spatial distribution of relative error percentage in Rrs (/sr) on 03 JAN 2017 and 23JAN2017 having low mean relative error percentage and high mean relative percentage.

SeaDAS quality flags allows examine the pixels which are sensitive to change in ozone concentration. Pixels with $2 \%$ of deviation have flagged as TURBIDW on 23 JAN 2017 scene can be seen in figure 6 .
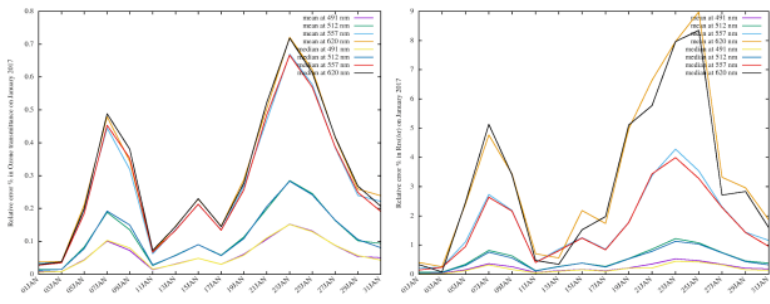

Figure 7: Mean and median of relative error percentage in Ozone transmittance (dimensionless) and Remote sensing reflectance (/sr) at $491 \mathrm{~nm}, 512 \mathrm{~nm}, 557 \mathrm{~nm}$ and $620 \mathrm{~nm}$ for January 2017

Due to vast number of pixels, plotted mean and median for individual days to see the consistency in relative error percentage. From this figure, we can observe the days having minimum and maximum relative error percentage in Ozone transmittance and remote sensing reflectance (/sr). $01 \mathrm{JAN}, 03$ JAN, 11 JAN are showing minimum and 23 and 25 JAN are showing maximum relative error percentage in Ozone transmittance at four bands.

\section{Conclusions}

At present OCM-2 operational ocean color processing uses climatology ancillary data for Ozone concentration to retrieve geophysical products. Near Real Time Ozone concentration is the alternative source to reduce the uncertainties. Based on the 
observation of $4 \%$ relative error in remote sensing reflectance (/sr) further analysis is required to see the impact of Ozone concentration on remote sensing reflectance in different seasons. $4 \%$ of deviation in $\operatorname{rrs}(/ \mathrm{sr})$ may reduce the quality of chlorophyll concentration to be analyzed extensively in future. There is a need to process the ocean color data with available Near Real Time parameters to represent current weather / atmospheric conditions.

\section{Acknowledgements}

This work was funded by NICES program ECSA/NRSC, ISRO. We thank NASA Ocean Biology Processing Group for providing SeaWiFS data Analysis System (SeaDAS) software to process the data, and ocean color web for providing ancillary data source of OZONE OMI-Aura. We thank Gnuplot which is a command line plotting tool allows to visualize the data and mathematical functions.

\section{References}

B. Franz, S. W. Bailey, P. J. Werdell, and C. R. McClain. Sensor-independent approach to the vicarious calibration of satellite ocean color radiometry. Appl. Optics, 46:5068-5082, 2007.

Curtis D. Mobley, Jeremy Werdell, Bryan Franz, Ziauddin Ahmad, and Sean Bailey, NASA/GSFC, "Atmospheric Correction for Satellite Ocean Color Radiometry" (NASA /TM 2016-217551

H. R. Gordon and M. Wang, "Retrieval of water-leaving radiance and aerosol optical thickness over the oceans with SeaWiFS: a preliminary algorithm," Appl. Opt. 33(3), 443-452 (1994)

H. R. Gordon, J. W. Brown, and R. H. Evans, "Exact Rayleigh scattering calculations for use with the Nimbus-7 Coastal Zone Color Scanner," Appl. Opt. 27(5), 862-871 (1988).

John E. O'Reilly, Stéphane Maritorena, B. Greg Mitchell, David A. Siegel, Kendall L. Carder Sara A. Garver, Mati Kahru, and Charles McClain "Ocean color chlorophyll algorithms for SeaWiFS" Journal of Geophysical Research, vol. 103, no. cll, pages $24,937-24,953$, october 15,1998

R. McPetersa*, R. Stolarskib , and S. Frith "A Long-Term Merged Global Ozone Data Set” isprs proceedings, 2011

Sathyadev Ramachandran and Menghua Wang "Near-RealTime Ocean Color Data Processing Using Ancillary Data From the Global Forecast System Model "IEEE transactions on Geoscience and Remote Sens., vol 49, no.4, April 2011.

Wayne Robinson, "A comparison of the new meteorological data to the currently used meteorological data" July 2014

Ozone Monitoring Instrument (OMI) Data User's Guide OMIDUG-5.0 January 5, 2012 Produced by OMI Team. 